\title{
Variability in distribution and use of tuberculosis diagnostic tests in Kenya: a cross-sectional survey
}

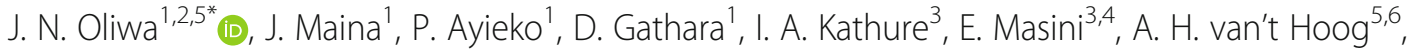
M. B. van Hensbroek ${ }^{5,6}$ and M. English ${ }^{1,7}$

\begin{abstract}
Background: Globally, 40\% of all tuberculosis (TB) cases, 65\% paediatric cases and 75\% multi-drug resistant TB (MDR-TB) cases are missed due to underreporting and/or under diagnosis. A recent Kenyan TB prevalence survey found that a significant number of TB cases are being missed here. Understanding spatial distribution and patterns of use of TB diagnostic tests as per the guidelines could potentially help improve TB case detection by identifying diagnostic gaps.

Methods: We used 2015 Kenya National TB programme data to map TB case notification rates (CNR) in different counties, linked with their capacity to perform diagnostic tests (chest X-rays, smear microscopy, Xpert MTB/RIF⿻, culture and line probe assay). We then ran hierarchical regression models for adults and children to specifically establish determinants of use of Xpert ${ }^{\oplus}$ (as per Kenyan guidelines) with county and facility as random effects.
\end{abstract}

Results: In 2015, 82,313 TB cases were notified and 7.8\% were children. The median CNR/100,000 amongst 0-14yr olds was 37.2 (IQR 20.6, 41.0) and 267.4 (IQR 202.6, 338.1) for $\geq 15 y$ olds respectively. 4.8\% of child TB cases and 12. $2 \%$ of adult TB cases had an Xpert ${ }^{\oplus}$ test done, with gaps in guideline adherence. There were 2,072 microscopy sites (mean microscopy density 4.46/100,000); 129 Xpert ${ }^{\oplus}$ sites (mean 0.31/100,000); two TB culture laboratories and 304 chest $X$-ray facilities (mean $0.74 / 100,000$ ) with variability in spatial distribution across the 47 counties. Retreatment cases (i.e. failures, relapses/recurrences, defaulters) had the highest odds of getting an Xpert ${ }^{\oplus}$ test compared to new/transfer-in patients (AOR 7.81, 95\% Cl 7.33-8.33). Children had reduced odds of getting an Xpert ${ }^{\oplus}$ (AOR 0.41, Cl 0.36-0.47). HIV-positive individuals had nearly twice the odds of getting an Xpert ${ }^{\oplus}$ test (AOR 1.82, Cl 1.73-1.92). Private sector and higher-level hospitals had a tendency towards lower odds of use of Xpert ${ }^{\oplus}$.

Conclusions: We noted under-use and gaps in guideline adherence for Xpert ${ }^{\circledR}$ especially in children. The under-use despite considerable investment undermines cost-effectiveness of Xpert ${ }^{\oplus}$. Further research is needed to develop strategies enhancing use of diagnostics, including innovations to improve access (e.g. specimen referral) and overcoming local barriers to adoption of guidelines and technologies.

Keywords: Tuberculosis, Diagnostics, Tests, Distribution, Use, Adults, Children

\footnotetext{
* Correspondence: joliwa@kemri-wellcome.org

${ }^{1}$ KEMRI-Wellcome Trust Research Programme, Nairobi, Kenya

${ }^{2}$ University of Nairobi, Department of Paediatrics and Child Health, Nairobi,

Kenya

Full list of author information is available at the end of the article
}

(C) The Author(s). 2018 Open Access This article is distributed under the terms of the Creative Commons Attribution 4.0 International License (http://creativecommons.org/licenses/by/4.0/), which permits unrestricted use, distribution, and reproduction in any medium, provided you give appropriate credit to the original author(s) and the source, provide a link to the Creative Commons license, and indicate if changes were made. The Creative Commons Public Domain Dedication waiver (http://creativecommons.org/publicdomain/zero/1.0/) applies to the data made available in this article, unless otherwise stated. 


\section{Background}

Globally, there is a significant $\mathrm{TB}$ case detection gap: $40 \%$ of all tuberculosis (TB) cases, $65 \%$ paediatric cases and $75 \%$ multi-drug resistant TB (MDR-TB) cases are missed due to a mixture of underreporting and under diagnosis [1-3]. Rapid and accurate diagnosis of TB is critical for timely initiation of treatment to prevent death [4-6]. A recent prevalence survey in Kenya found higher rates of TB than previously thought (558/ $100,000)$, with up to $55 \%$ of cases being missed probably due to under-detection [7]. Three quarters of the positive TB cases identified in the survey reported seeking care for TB-like symptoms but were not diagnosed. The survey recruited $\geq 15 \mathrm{yr}$ olds, but extrapolation from adult data showed that two thirds of paediatric TB cases were missed [7]. Notification data may underestimate child TB incidence, which may be explained in part by poor reporting of diagnosed paediatric cases [8]; and challenges of diagnosing TB in children due to paucibacillary disease and difficulty obtaining suitable samples $[9,10]$.

Quicker, more sensitive TB diagnostic technologies are being introduced globally [4, 11]. In 2010, Xpert MTB/ $\mathrm{RIF}^{\odot}$ was initially endorsed by the World Health Organisation (WHO) for children, the HIV infected and suspected MDR-TB cases [12], but is now recommended as the first line diagnostic test for all presumed TB cases $[13,14]$. Kenya introduced Xpert ${ }^{\oplus}$ in 2011. According to the guidelines used in Kenya in 2015 (when this study was done), all presumptive paediatric, HIV-infected smear negative, drug resistant (DR) cases, or retreatment cases i.e. relapse (recurrence)/defaults/treatment failures should have had at least one Xpert ${ }^{\ominus}$ assay as part of their diagnostic work up (Additional file 1) [15, 16]. By 2015, there were 129 machines distributed throughout the country (146 machines to date), with more expected [17]. Optimal use of $\mathrm{Xpert}^{\oplus}$ is important for TB case detection $[18,19]$. Few studies have specifically reviewed spatial distribution and practices in the utilisation of bacteriological TB diagnostic tests like Xpert ${ }^{\oplus}$ comparing adults and children, in countries that carry a high TB/ MDR burden like Kenya.

A multi-country study on gaps in reporting paediatric TB found children were rarely considered for testing [20]. Age, gender, poverty and literacy are known to influence general health care utilisation and demand for services [21, 22]. One study found socioeconomic status and prior anti-TB treatment were strong determinants of utilisation of bacteriological tests [23]. Behavioural or health system issues may also play a role where services are available but underutilised- perhaps due to patients' lack of awareness or perceived poor quality [22, 24-26].

Seeking to understand and improve TB case detection in Kenya, we set out to: describe the characteristics and spatial distribution of $\mathrm{TB}$ cases reported to the $\mathrm{TB}$ programme; the availability, distribution and patterns of use of TB diagnostic tests as per Kenyan guidelines [15, 16]; and to establish the determinants of use of Xpert ${ }^{\bullet}$, noting differences in adults and children in the various counties. To the best of our knowledge, this is the first attempt to describe in detail the utilisation of TB diagnostics in Kenya, comparing adults and children to try to unmask the "hidden epidemic" of TB [27]. Findings will hopefully help guide policy makers on where the greatest needs are, how well guidelines are being implemented and offer suggestions to mitigate gaps identified. As new tests emerge [28], understanding patterns and determinants of use could help reduce TB deaths by guiding early diagnosis and linkage to appropriate treatment.

\section{Methods}

\section{Setting}

Kenya is administratively divided into 47 counties, that are now largely responsible for health care since devolution in 2013 [29]. Health services are provided by public, private, non-profit non-governmental organisations (NGO) and faith based organisations (FBO). The healthcare system is structured in a hierarchical manner, starting with primary healthcare in the community and complicated cases referred upwards to secondary and tertiary levels of healthcare [29]. According to the Kenyan Master Facility List, there are approximately 10,000 health facilities in the country and just about half are TB treatment sites [30-32]. For this analysis, we aggregated TB health facilities into two: lower level (dispensaries, health centres, and maternity/nursing homes) for primary care; and higher level (county hospitals and national referral facilities) that provide secondary and tertiary referral services.

\section{Study Population}

We included patients of all ages who were notified to the Kenya National TB programme and started TB treatment in 2015.

\section{Study variables}

We wished to explore the possible influence on use of Xpert MTB/RIF ${ }^{\circledast}$ of variables in three hierarchical levels: county, health facility and individual. Individual level co-variates included: age; gender; HIV status; nutritional status; and type of TB patient i.e. new/transfer-in or retreatment cases (relapse/defaults/treatment failures). An age cut-off of $15 y$ rs for children is used locally and internationally for TB programming [14], therefore "child" here refers to $0-14 y$ r olds. For nutrition status, weight-for-age Z (WAZ) scores were computed for those aged $0-23 y r$ and body mass index (BMI) truncated at -5 to $+5 \mathrm{SD}$ for those $\geq 10 \mathrm{yr}$, and patients classified as underweight according to the scores. Those 10-23yr who 
met criteria of underweight by either criterion were also classified as underweight. Health facility level co-variates included: sector of care (public, private, or FBOs), level of care provided (higher vs lower level) and whether they were an Xpert ${ }^{\circ}$ site or not. County level co-variates included: poverty; maternal education levels; travel time to nearest health facilities; and availability of $\mathrm{Xpert}^{\circ}$ facilities per 100,000. All co-variates were determined for each of the 47 counties for 2015. These factors were decided upon a priori following review of literature on drivers of use of $\mathrm{TB}$ and health care services in general and data availability $[21,22]$.

The primary outcome of interest was evidence of Xpert ${ }^{\circ}$ being done in patients who had been started on TB treatment. According to the 2015 Kenyan guidelines, all presumptive paediatric, HIV-infected smear negative, drug resistant (DR) cases, or retreatment cases i.e. relapse (recurrence)/defaults/treatment failures should have had at least one Xpert ${ }^{\circ}$ assay as part of their diagnostic work up (Additional file 1) [15, 16].

\section{Data sources}

We considered the best data sources for the three levels of variables of interest. For the individual level, de-identified data from the Kenya National TB Programme patients' treatment register for 2015 were used (patients who were notified and/or started treatment in 2015). TB case definitions were as per Guidance for National TB programmes (Additional file 1) [33]. Health facility level data were from the Kenya Master Health Facility list [30] and Kenya Services Availability and Readiness Assessment Mapping Report (SARAM) 2014 [34]. Health facilities in the national TB register were geocoded using KEMRI-Wellcome Trust's Kenya Health Facilities Database, which was last updated in 2016 using online digital place-name gazetteers and Global Positioning System (GPS) sources. County level data were from each county governments' integrated development plans for 2015 [35]. The projected 2015 Kenya gridded population distribution surface at $100 \mathrm{~m}$ spatial resolution was obtained from the WorldPop project $[36,37]$.

\section{Statistical and Spatial Analysis}

Stata version 15MP (StataCorp.2017, College Station, TX, USA) and ArcGIS 10.5 (ESRI, Redlands, CA, USA) were used for statistical analysis, and mapping and spatial analysis respectively. We described the proportion of adults and children reported to the TB programme, their socio-demographic characteristics, use of TB diagnostic tests and outcomes. We used the 2015 Kenya National TB programme data to construct maps for each TB case notification rate (CNR) in different counties and linked this with their capacity to perform diagnostic tests (chest $\mathrm{x}$-rays, smear microscopy, Xpert', culture and line probe assay) from the SARAM report [34].

For adherence to guidelines, we only had data for those who had tests done, and used these patients to describe patterns of use of TB diagnostic tests. Co-variates of theoretical and/or statistical significance were used to build hierarchical logistic regression models to establish determinants of use of $\mathrm{Xpert}^{\circ}$ in adults and children. Possible collinearity was assessed using the variance inflation factor (VIF). Variables with VIF less than 10 were considered for analysis. The models converged at five integration points for complete case analysis, with county and health facility as random effects [38]. Models were built for the $0-14 y r s$ and $\geq 15 y$ rs separately and a model for the total population, with likelihood ratio tests, exploration for interactions in pre-specified covariates (HIV and nutrition status) and quantile-quantile plots of residuals used to determine best fit as seen in Additional file $2[38,39]$.

\section{Results}

Data were available from 82,313 patients who started TB treatment in 2015. Table 1 gives the characteristics of these patients for the different age bands and overall population. There were 6,450 children aged $0-14 \mathrm{yr}$, and they represented $7.8 \%$ of the total population. In the overall population, $62.4 \%(51,337)$ were male, and they were $3,406(52.8 \%)$ in the $0-14 y r$ group. Most of the patients were from the public sector. TB was pulmonary in approximately three quarters of all the patients. A quarter of patients 0-14yrs were HIV infected compared with a third of those $\geq 15 y$ rs. Overall, close to half the patients were underweight. Close to $10 \%$ of those $\geq 15 \mathrm{yrs}$ needed TB retreatment (i.e. failures, relapses/recurrences, defaulters). Less than $5 \%(309 / 6,450)$ of patients $0-14 \mathrm{yrs}$ and $12.2 \%(9,224 / 75,863)$ of patients $\geq 15 \mathrm{yrs}$ had an $\mathrm{Xpert}^{\circ}$ done. The proportion of positive Xpert ${ }^{\circ}$ tests was $63.1 \%(195 / 309)$ for the $0-14 \mathrm{yr}$ and $81.2 \%(7,493 / 9,224)$ for the $\geq 15 y$ ys old; while microscopy was positive in $36.7 \%(694 / 1,886)$ vs $67.1 \%(40,768 / 60,797)$ for $0-14 y r s$ vs the $\geq 15 y$ rs respectively. Overall case fatality was between $4-6 \%$ for both groups.

\section{Patterns of use of TB diagnostics tests}

Figure 1 illustrates diagnostic practices amongst those patients who were started on anti-TB treatment. More than a third of children $0-14 \mathrm{yr}$ had no diagnostic test done, and were started on treatment based on clinical diagnosis only. Chest X-ray was the commonly used test in this age group (37.1\%); while microscopy was the commonest amongst the $\geq 15 y$ rs. Table 2 illustrates the patterns of use of bacteriological tests amongst those who had these tests done, relating them to the 2015 
Table 1 Characteristics of Patients notified to the Kenyan National TB Programme in 2015

\begin{tabular}{|c|c|c|c|}
\hline & $\begin{array}{l}0-14 y r s \mathrm{n}(\%) \\
(\mathrm{N}=6450)\end{array}$ & $\begin{array}{l}\geq 15 y r s n(\%) \\
(N=75863)\end{array}$ & $\begin{array}{l}\text { Overall population } \mathrm{n}(\%) \\
(\mathrm{N}=82313)\end{array}$ \\
\hline \multicolumn{4}{|l|}{ Gender } \\
\hline Male & $3406(52.8)$ & $47931(63.2)$ & $51337(62.4)$ \\
\hline Female & $3044(47.2)$ & $27932(36.8)$ & $30976(37.6)$ \\
\hline \multicolumn{4}{|l|}{ Sector } \\
\hline Public & 4938 (76.6) & $59165(78.0)$ & $64103(77.9)$ \\
\hline Prisons & $41(0.6)$ & $1349(1.8)$ & $1390(1.7)$ \\
\hline Private & $1343(20.8)$ & $14010(18.5)$ & $15353(18.7)$ \\
\hline Faith based and others & $128(2.0)$ & $1339(1.8)$ & $1467(1.8)$ \\
\hline \multicolumn{4}{|l|}{ TB Type } \\
\hline Pulmonary & $4774(74.0)$ & $62964(83.0)$ & $67738(82.3)$ \\
\hline Extra-pulmonary & $1676(26.0)$ & $12899(17.0)$ & $14575(17.7)$ \\
\hline \multicolumn{4}{|l|}{ HIV testing } \\
\hline Negative & $4517(70.0)$ & $49016(64.6)$ & $53533(65.0)$ \\
\hline Positive & $1610(25.0)$ & $24980(32.9)$ & $26590(32.3)$ \\
\hline Unknown & $323(5.0)$ & $1867(2.5)$ & $2190(2.7)$ \\
\hline \multicolumn{4}{|l|}{ Anthropometry (BMI) } \\
\hline Underweight ${ }^{a}$ & $2951(45.8)$ & $35274(46.5)$ & $38225(46.4)$ \\
\hline Normal & $2777(43.1)$ & $31338(41.3)$ & $34115(41.5)$ \\
\hline Overweight/obese & $22(0.34)$ & 2929 (3.9) & $2951(3.4)$ \\
\hline Undocumented & $700(10.9)$ & $6322(8.3)$ & $7022(8.5)$ \\
\hline \multicolumn{4}{|l|}{ Type of patient } \\
\hline New & $6233(96.6)$ & $68470(90.3)$ & $74703(90.8)$ \\
\hline Transfer in & $40(0.6)$ & $788(1.0)$ & $828(1.0)$ \\
\hline Relapse (recurrence) & $144(2.2)$ & $5383(7.1)$ & $5527(6.7)$ \\
\hline Default & $33(0.5)$ & $999(1.3)$ & $1032(1.3)$ \\
\hline Failure & $0(0)$ & $223(0.3)$ & $223(0.3)$ \\
\hline \multicolumn{4}{|l|}{ Chest-X-ray } \\
\hline Done & $3140(48.7)$ & $22141(29.2)$ & $25281(30.7)$ \\
\hline Not done & $3310(51.3)$ & $53722(70.8)$ & $57032(69.3)$ \\
\hline \multicolumn{4}{|l|}{ Smear Microscopy } \\
\hline Done & $1886(29.2)$ & $60797(80.1)$ & $62,683(76.2)$ \\
\hline Positive $^{b}$ & $694(36.7)$ & $40768(67.1)$ & $41462(66.1)$ \\
\hline Negative $^{b}$ & $1192(63.2)$ & $20029(32.9)$ & $21221(33.9)$ \\
\hline \multicolumn{4}{|l|}{ Xpert MTB/RIF ${ }^{\oplus}$} \\
\hline Done & $309(4.8)$ & $9224(12.2)$ & $9533(11.6)$ \\
\hline Positive (Rif-Sensitive) ${ }^{\mathrm{b}}$ & $195(63.1)$ & $7493(81.2)$ & $7688(80.6)$ \\
\hline Positive (Rif-Resistant) ${ }^{\mathrm{b}}$ & $1(0.3)$ & $129(1.4)$ & $130(1.4)$ \\
\hline Negative $^{b}$ & $113(36.6)$ & $1602(17.4)$ & $1715(18.0)$ \\
\hline \multicolumn{4}{|c|}{ Culture/Line Probe Assay (LPA) } \\
\hline Done & $5(0.1)$ & $444(0.6)$ & $449(0.5)$ \\
\hline Drug susceptible ${ }^{b}$ & $5(100)$ & $371(83.6)$ & $376(83.7)$ \\
\hline Drug resistant ${ }^{\mathrm{b}}$ & $0(0.0)$ & 73 (16.4) & $73(16.3)$ \\
\hline
\end{tabular}


Table 1 Characteristics of Patients notified to the Kenyan National TB Programme in 2015 (Continued)

\begin{tabular}{llll}
\hline & $\begin{array}{l}0-14 y \text { rs } n(\%) \\
(\mathrm{N}=6450)\end{array}$ & $\begin{array}{l}\geq 15 y \text { rs } \mathrm{n}(\%) \\
(\mathrm{N}=75863)\end{array}$ & $\begin{array}{l}\text { Overall population } \mathrm{n}(\%) \\
(\mathrm{N}=82313)\end{array}$ \\
\hline $\begin{array}{l}\text { Outcome } \\
\text { Cured }\end{array}$ & $537(8.3)$ & $31416(41.4)$ & $31953(38.8)$ \\
Died & $270(4.2)$ & $4391(5.8)$ & $4661(5.7)$ \\
Treatment failure & $1(0.02)$ & $429(0.6)$ & $430(0.5)$ \\
Other $^{c}$ & $5642(87.5)$ & $39627(52.2)$ & $45269(55 \%)$ \\
\hline
\end{tabular}

anderweight defined as either WAZ $<-2 \mathrm{SD}$ or $\mathrm{BMI}<18.5$ as appropriate for age

${ }^{\mathrm{b}}$ Percentage in brackets represent proportions amongst those who got the test done

'Other included: treatment not completed; completed but not cured; defaulted; transferred out

Kenyan guidelines (Additional file 1). Children 0-14yr represented $<5 \%$ of those who had either $\mathrm{Xpert}^{\circ}$ or Microscopy or Culture/LPA done. Those with extrapulmonary $\mathrm{TB}$ also rarely got any of the tests done. Retreatment cases got a culture/LPA done more than any other test. Forty one percent of the patients got Xpert ${ }^{\circ}$ as per guidelines, with better guideline adherence for culture/LPA (61.2\%) and microscopy (97.8\%), respectively.

\section{Tuberculosis Case Notification Rates and distribution of TB cases in Kenya}

Figures 2 and 3 and Additional files 3 and 4 show case notification rates (CNR) by age group and county, as well as variation in county use of $\mathrm{Xpert}^{\circ}$ and microscopy. Median age was 32yr (IQR 24yr, 43yr). The highest CNR was amongst those $35-44 y r s(455 / 100,000)$, and the lowest amongst the 5-9yrs $(27 / 100,000)$ Fig. 2. The median CNR/100,000 amongst children 0-14yr old was 37.2 (IQR 20.6, 41.0) and 267.4 (IQR 202.6, 338.1) for $\geq 15 \mathrm{yr}$ olds respectively. Median use of $\mathrm{Xpert}^{\circ}$ among 0-14yr olds was $1.45 / 100,000$ (IQR $0.7,2.1$ ) and in $\geq 15 \mathrm{yr}$ olds was 29.9/100,000 (IQR 21.0, 42.8). Median use of microscopy among 0-14yr olds was 8.1/100,000 (IQR 6.6, 12.8 ) and $222 / 100,000$ (IQR $169.8,270.4$ ) in $\geq 15 y r$ olds. Xpert $^{\circ}$ use did not correlate with increase in county TB $\mathrm{CNR} / 100,000$ (Fig. 3 and Additional file 4) and in this was also observed in the univariate analysis where counties with higher $\mathrm{Xpert}^{\circ}$ density did not have significantly higher CNRs (Additional file 2). Microscopy use in the $\geq 15 \mathrm{yr}$ tended to be higher in counties with highest CNRs (Fig. 3 and Additional file 4).

Figure 4 shows a panel of maps illustrating spatial distribution of TB patients in Kenya. The counties with two
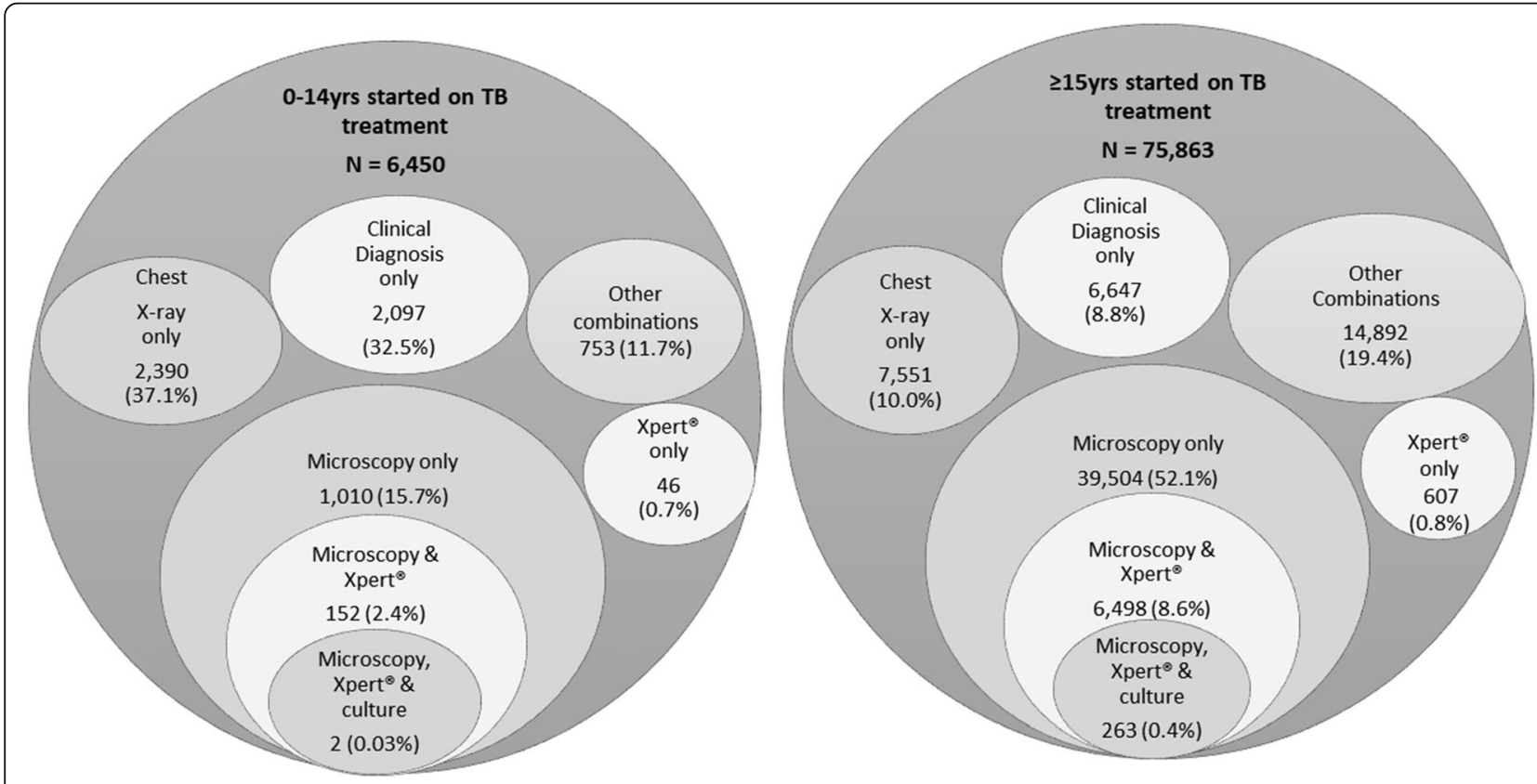

$N / B$ the percentages are a proportion of the total frequency in each age group

Fig. 1 Diagnostic practices amongst patients started on TB treatment in 2015 
Table 2 Patterns of use of TB diagnostics and compared to recommended Kenyan TB guidelines in use in 2015

\begin{tabular}{|c|c|c|c|}
\hline \multirow[t]{2}{*}{ Characteristic } & $\begin{array}{l}\text { Xpert }^{\circledR} \text { done }^{a} \\
N=9,553\end{array}$ & $\begin{array}{l}\text { Microscopy done }{ }^{b} \\
N=62,683\end{array}$ & $\begin{array}{l}\text { Culture/LPA donec } \\
N=515\end{array}$ \\
\hline & n (\%) & n (\%) & n (\%) \\
\hline \multicolumn{4}{|l|}{ Age } \\
\hline $0-14 \mathrm{yr}$ & $309(3.2)$ & $1886(3.0)$ & $5(1.0)$ \\
\hline$\geq 15 \mathrm{yr}$ & $9224(96.8)$ & $60797(97.0)$ & $510(99.0)$ \\
\hline \multicolumn{4}{|l|}{ Gender } \\
\hline Male & $6152(64.5)$ & $40128(64.0)$ & $385(74.8)$ \\
\hline \multicolumn{4}{|l|}{ Type of TB } \\
\hline Pulmonary & 9205 (96.6) & $61320(97.8)$ & $508(98.6)$ \\
\hline Extrapulmonary & $328(3.4)$ & $1363(2.2)$ & $7(1.4)$ \\
\hline \multicolumn{4}{|l|}{ Type of patient } \\
\hline New/transfer in & $6774(71.1)$ & $56821(90.7)$ & $200(38.8)$ \\
\hline Retreatment (relapse/defaults/treatment failures) & $2759(28.9)$ & $5862(9.3)$ & $315(61.2)$ \\
\hline Test done as per guideline & $3909^{\mathrm{a}}(41.0)$ & $61320^{\mathrm{b}}(97.8)$ & $315^{\mathrm{C}}(61.2)$ \\
\hline
\end{tabular}

Excerpt from 2015 Kenyan guidelines

${ }^{\text {a Xpert }}{ }^{\oplus}$ recommended for all presumptive paediatric TB OR HIV-infected smear negative OR drug resistant cases OR retreatment cases i.e. relapse/defaults/ treatment failures in adults OR suspected drug resistant TB

${ }^{\mathrm{b}}$ Microscopy recommeded for all recommended pulmonary tuberculosis cases

${ }^{\mathrm{C} C}$ ulture/LPA recommended for retreatment cases ((i.e. relapse/defaults/treatment failures) regardless of age

large cities had some of the highest CNRs, as did two counties serving the pastoralist communities of the northern and eastern frontiers (panel A). Panel B and C show the CNRs in the $\geq 15 y$ r olds ("Adults") and in children $0-14 \mathrm{yr}$ old respectively, while $\mathrm{D}$ shows the ratio of adult to child TB cases. These maps highlight some of the adult hot spots with low child CNRs and ensuing differences in adult: child ratios highlighting the gaps in case detection for children.

Figure 5 and Additional file 5 show the distribution of facilities with TB diagnostic facilities (Microscopy-Map A;
Xpert MTB/RIF ${ }^{-}$-Map B; Culture and Line Probe AssayMap C; and chest X Ray-Map D) overlaid with each county's total population density. In 2015, there were 129 facilities providing Xpert ${ }^{\circ}$ services (mean Xpert ${ }^{\circ}$ density of $0.28 / 100,000$ ); 304 chest $\mathrm{X}$ ray facilities (mean density $0.67 /$ 100,000); and 2,072 facilities with microscopy services (mean density 4.54/100,000). There were disparities noted in the distribution of Xpert $^{\circ}$ (panel B) and chest X-ray (panel D) facilities with some northern and eastern counties of Kenya having low facility densities/100,000 yet they carry a high burden of TB cases (Fig. 4).

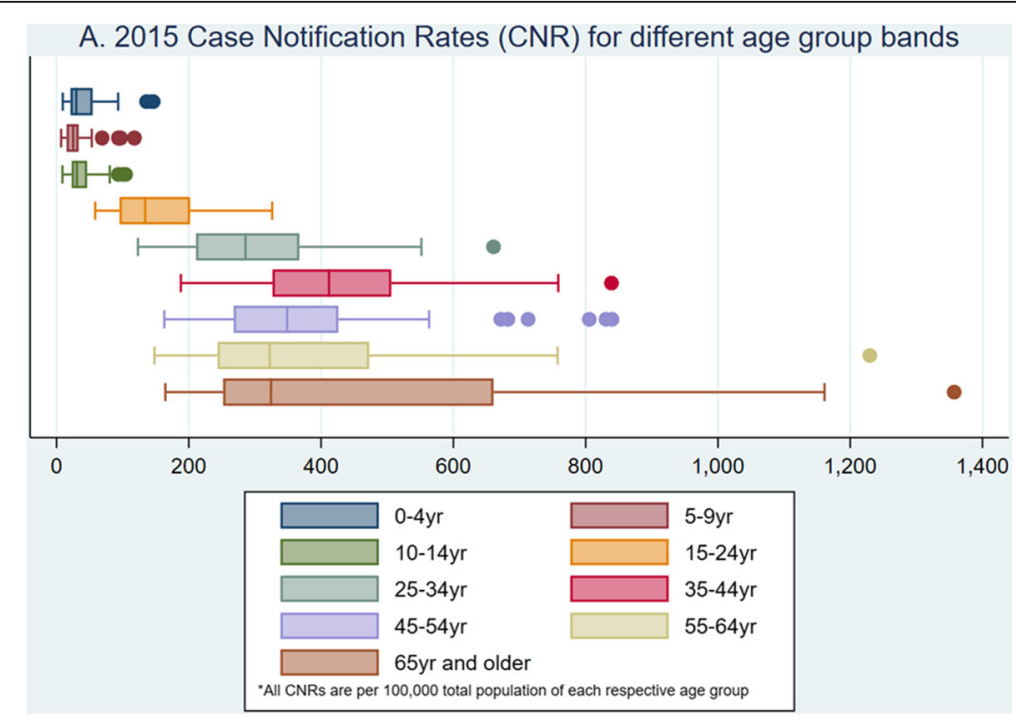

Fig. 2 TB Case Notification Rates (CNRs) for different age group bands in Kenya 


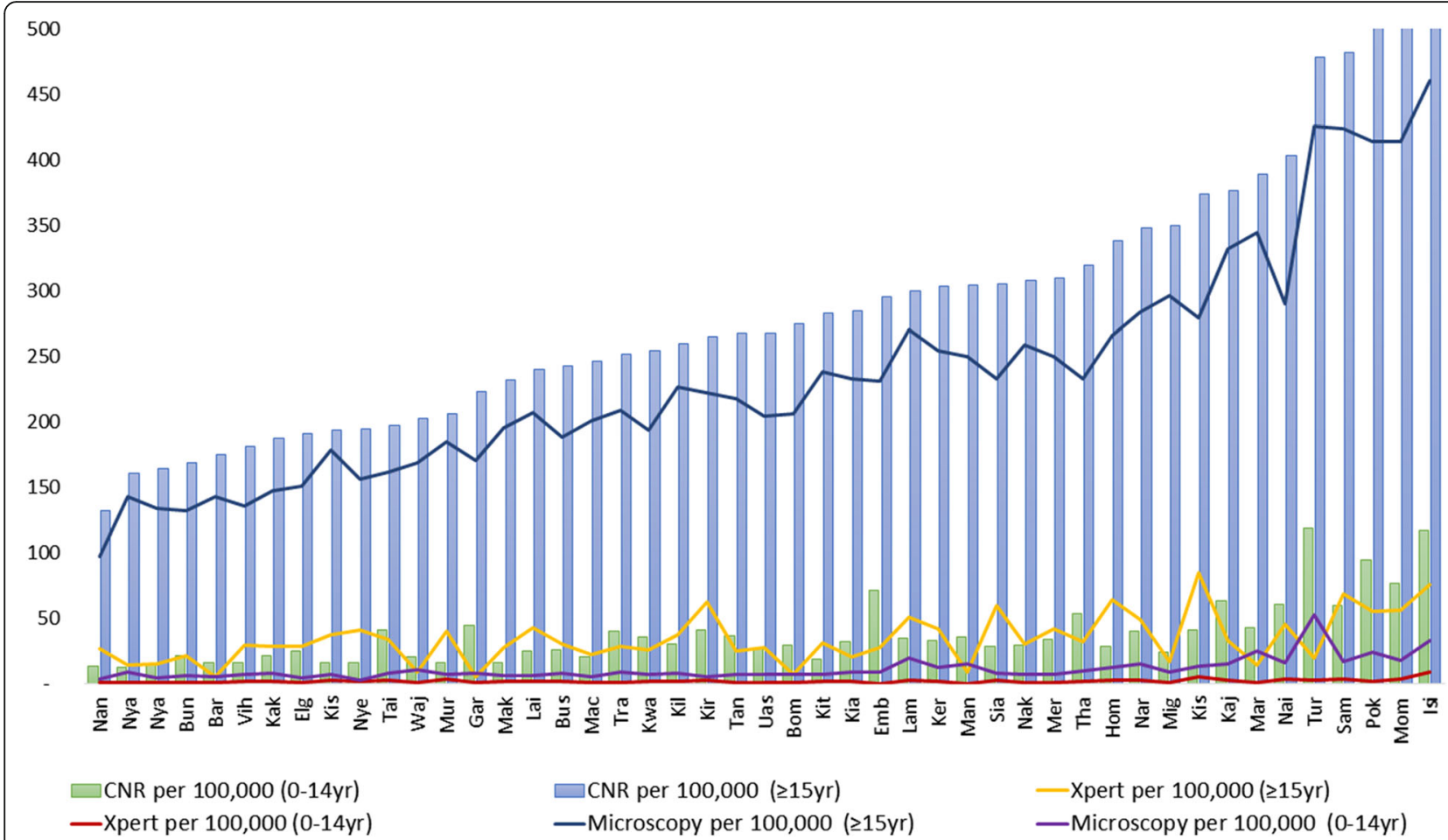

Fig. 3 Chart showing variability of County TB CNRs and use of Xpert ${ }^{\circledR}$ and Microscopy per 100,000 population comparing adults and children (Full county names and variables in Additional file 4)

\section{Determinants of use bacteriological TB diagnostic tests comparing adults and children}

Additional file 2 shows the univariate analysis of the factors that had been considered for the model building, and Table 3 shows the final adjusted hierarchical models of determinants of use of $\mathrm{Xpert}^{\ominus}$ in adults and children, with county and health facility as random effects. Amongst individual level factors, the retreatment cases (i.e. failures, relapses/recurrences, defaulters) had the highest odds of getting an $\mathrm{Xpert}^{\oplus}$ (total population AOR 7.81, 95\% CI 7.33 to 8.33 ). From the model of the total population, children had reduced odds of getting an Xpert ${ }^{\oplus}$ test (AOR 0.41, CI 0.36 to 0.47 ), while being male was associated with increased odds in all age groups. Overall, the HIV positive individuals had nearly twice the odds of getting an Xpert ${ }^{\circ}$ compared to the HIV negative. Nutrition status had a marginal effect, except in the $0-14 y$ r olds where the underweight group had nearly twice the odds of getting an Xpert $^{\circ}$ compared with the well-nourished cases.

Examining factors at the facility and county levels, patients in private sector and from higher level facilities had a tendency towards lower odds of getting tested compared with those in public sector or lower level facilities, but this difference was not statistically significant for the $0-14 y$ rs old. We also noted that counties with higher Xpert ${ }^{\oplus}$ density did not report significantly higher CNRs. From the intra-class correlation coefficients (ICC), county as a level explained approximately 4 \& $7 \%$ and health facility 24 \& $26 \%$ of the observed variability in each adjusted model.

\section{Discussion}

We set out to describe the spatial distribution of TB patients and TB diagnostic services, and patterns of use of $\mathrm{TB}$ diagnostic tests in Kenya as per the guidelines (with emphasis on Xpert $\mathrm{MTB} / \mathrm{RIF}^{\oplus}$ ), noting differences in children and adults. The TB case notification rate (CNR) in children 0-14yrs was nearly eight times less than that of those $\geq 15 y r s$, which may imply under detection. Children are thought to represent $10-20 \%$ of the total reported TB cases in high TB endemic settings like Kenya, but we observed only $7.8 \%$ in our data [40, 41]. Low CNR among children could additionally be explained by underreporting due to difficulties in confirming a diagnosis of TB in them and poor surveillance [2].

We observed wide county variation in distribution and use of TB diagnostic tests, as well as in case notification rates. Some of the northern and eastern counties had high TB CNRs, but a lower density/100,000 of facilities equipped with TB diagnostic services. Conversely, some counties had higher facility densities but reported lower rates of use. Kenya's health system has been affected by devolution and decentralisation of health services, and this could be having a bearing on TB care [42]. A recently published patient pathway analysis in Kenya found distinct variation in 


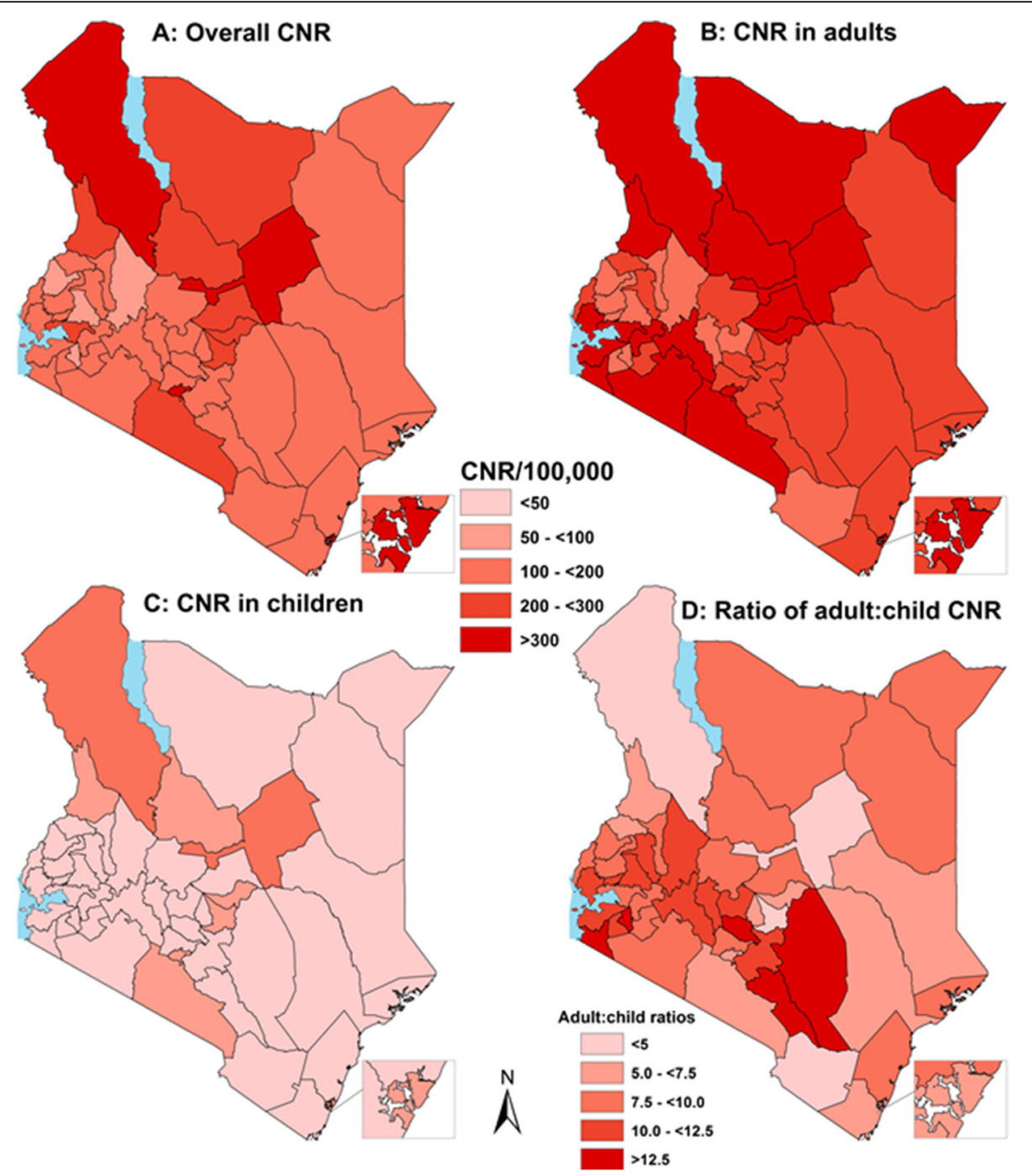

Fig 4 Maps illustrating the spatial distribution of TB patients in various counties in Kenya by: Overall population CNR/100,000 (a); CNR/100,000 in "adults" i.e. $\geq 15 y$ rs (b); CNR/100,000 in children 0-14yrs (c); and ratio of adult: child TB CNRs (d)

diagnostic and treatment availability across counties and facility levels [32].

To comply with existing guidelines at the time, all presumed child TB cases, HIV infected adults and suspected MDR-TB cases and retreatment cases should have had at least an $\mathrm{Xpert}^{\circ}$ done as part of the diagnostic work up $[15,16]$. We noted underutilisation, with less than $5 \%$ of patients 0 - $14 \mathrm{yrs}$ and $12.2 \%$ of patients $\geq 15 \mathrm{yrs}$ having an Xpert MTB/RIF ${ }^{\bullet}$ test done, with gaps in guideline adherence. Many children, however, had smear microscopy done, on a specimen that presumably could have been used for Xpert ${ }^{\circ}$. The assay has much better sensitivity than smear microscopy and can identify rifampicin resistance with much faster turn-around time than traditional culture, and has been shown to be cost effective [43-46]. The Kenya prevalence survey found that when microscopy was used alone, up to $50 \%$ of $\mathrm{TB}$ cases were being missed, while Xpert $\mathrm{MTB} / \mathrm{RIF}^{\circ}$ detected $78 \%$ of TB cases [7]. While use of Xpert ${ }^{\circ}$ is encouraged as the more sensitive test, it still misses approximately $22 \%$ of TB cases, and a negative Xpert ${ }^{\circ}$, especially in children does not rule out TB [43, 44]. However, if health workers can get sputum for microscopy especially in children, then they should ideally be able to send the sample for Xpert ${ }^{\circ}$, the recommended first-line test.

From the regression analysis, retreatment cases (i.e. failures, relapses/recurrences, defaulters) had the greatest odds of getting an $\mathrm{Xpert}^{\circ}$ as expected from the guidelines, as did those who were HIV infected after adjusting for other covariates. Children had reduced odds of getting tested, despite the recommendation that all should have had an Xpert'. There is, however, no documentation of failed attempts to test. 

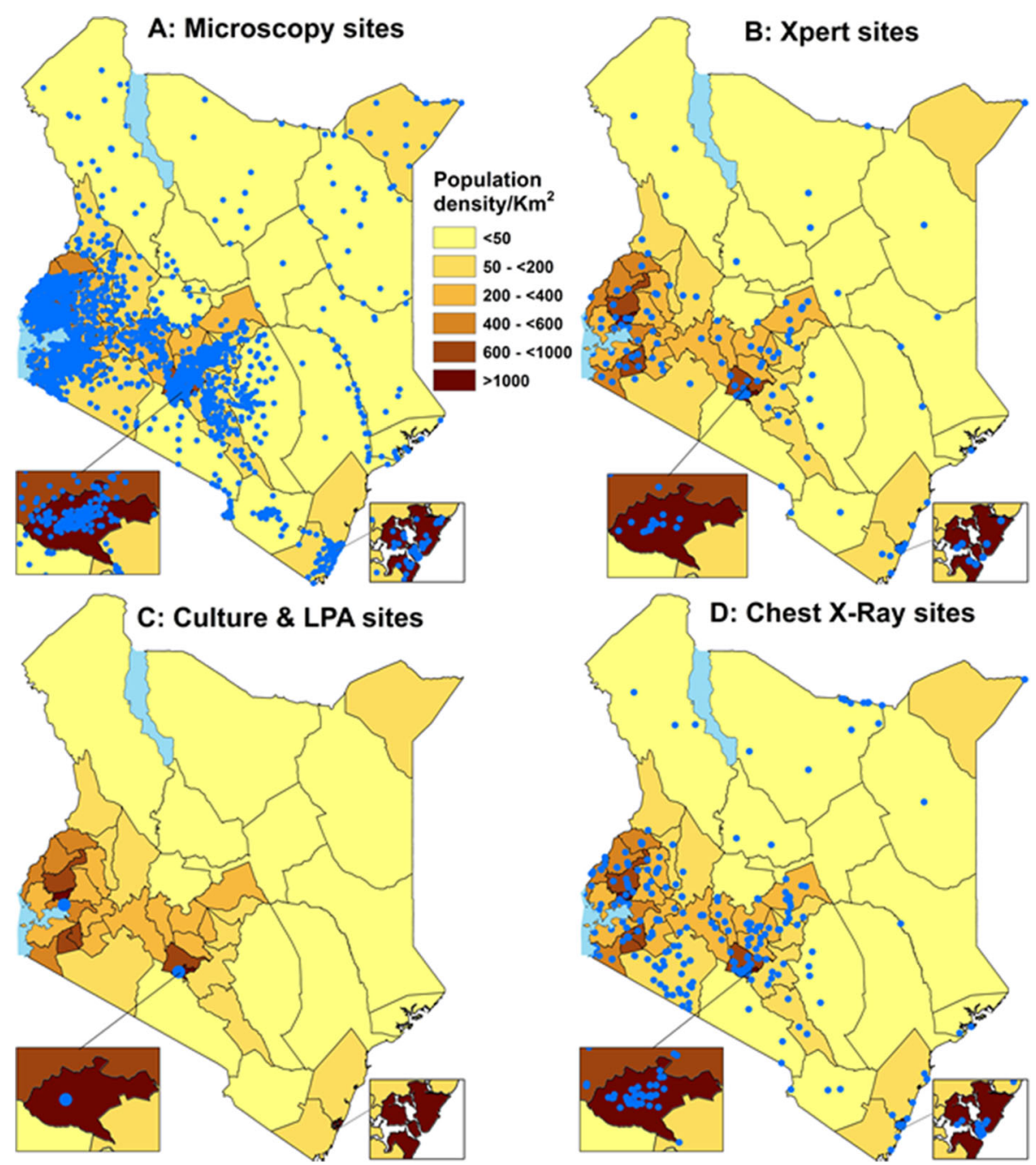

Fig. 5 Maps illustrating the distribution of facilities with TB diagnostic capabilities by: Microscopy (a); Xpert MTB/RIF ${ }^{\circledR}$ (b); Culture and Line Probe Assay Labs (c); and Chest X-ray (d), all overlaying each county's population density in 2015 as the background

Low utilisation of Xpert ${ }^{\circ}$ has been illustrated in other low income, high TB burden countries both in adults and children [47-49]. From surveys of implementation in high TB burden countries including Kenya, reasons associated with low utilisation included operational issues like power outages and poor specimen referral; doubts about impact to TB morbidity and mortality; preference to trust clinical acumen; low sensitivity especially in children; challenges in getting good specimens and false negatives; and lack of awareness amongst health care workers and patients [45, 48, 50]. In Kenya, $\mathrm{Xpert}^{\circ}$ sensitisation was initially done for lab staff only, which could have led to less demand for the test from clinicians. Some studies identified that training, workload, administrative support, staff motivation, role models and participation in the guideline development influence the implementation of TB guidelines in general [51-53].
Patients from higher level facilities had a tendency towards reduced odds of getting an $\mathrm{Xpert}^{\circ}$ done. This could be because they get patients already being worked up from lower level facilities being referred to them to manage complications. The Kenya TB patient pathway analysis paper found that $58 \%$ of patients sought care in lower level facilities [32]. The Kenya SARAM report found only $60 \%$ of Kenya's health facilities were ready to provide Kenya Essential Package for Health-defined TB services [34]. Readiness was found to be highest at the primary care facilities and in public facilities [34]. This is unlike in more wellresourced low TB burden countries, where TB care is at tertiary level facilities, and most patients have access to molecular diagnostic tests [54]. Private sector patients also had a tendency toward reduced odds of getting tested compared to public sector patients. This 
Table 3 Determinants of use Xpert/MTB/RIF ${ }^{\circledR}$ in Kenya

\begin{tabular}{|c|c|c|c|c|c|}
\hline Characteristic & $\begin{array}{l}\text { 0-14yrs } \\
\text { Xpert }{ }^{\oplus} \text { done } \\
\text { n (column \%) } \\
N=309\end{array}$ & $\begin{array}{l}\geq 15 y r s \\
\text { Xpert }^{\oplus} \text { done } \\
\text { n (column \%) } \\
N=9,224\end{array}$ & $\begin{array}{l}\text { Model } 1 \\
0-14 y r s \\
\text { adjusted OR } \\
(95 \% \mathrm{Cl}) \\
N=6,450\end{array}$ & $\begin{array}{l}\text { Model } 2 \\
\geq 15 y r s \\
\text { adjusted OR } \\
(95 \% \mathrm{Cl}) \\
N=75,845\end{array}$ & $\begin{array}{l}\text { Model } 3 \\
\text { Overall } \\
\text { adjusted OR } \\
(95 \% \mathrm{Cl}) \\
N=82,295\end{array}$ \\
\hline Age & & & & & $\begin{array}{l}1 \text { ( } \geq 15 y \text { ys base) } \\
0.41 \text { (0.36 to } 0.47)\end{array}$ \\
\hline \multicolumn{6}{|l|}{ Gender } \\
\hline Female & $140(45.3)$ & $3241(35.1)$ & 1 (base) & 1 (base) & 1 (base) \\
\hline Male & $169(54.7)$ & $5983(64.9)$ & 1.13 (0.88 to 1.45$)$ & 1.09 (1.03 to 1.14$)$ & 1.09 (1.03 to 1.14$)$ \\
\hline \multicolumn{6}{|l|}{ HIV Status } \\
\hline Negative & $164(53.1)$ & $4751(51.5)$ & 1 (base) & 1 (base) & 1 (base) \\
\hline Positive & $143(46.3)$ & $4372(47.4)$ & 2.00 (1.52 to 2.61$)$ & 1.83 (1.74 to 1.93$)$ & 1.82 (1.73 to 1.92$)$ \\
\hline Unknown & $2(0.7)$ & $101(1.1)$ & 0.19 (0.05 to 0.78$)$ & 0.81 (0.65 to 1.01$)$ & 0.76 (0.61 to 0.94$)$ \\
\hline \multicolumn{6}{|l|}{ Nutrition Status } \\
\hline Normal & $40(12.9)$ & 3379 (36.6) & 1 (base) & 1 (base) & 1 (base) \\
\hline Underweight & $238(77.0)$ & $5132(55.6)$ & 1.97 (1.36 to 2.83$)$ & 1.13 (1.07 to 1.19$)$ & 1.15 (1.09 to 1.21$)$ \\
\hline Overweight/obese & $3(1.0)$ & $360(3.9)$ & 0.94 (0.26 to 3.36$)$ & 0.88 (0.77 to 0.99 ) & 0.88 (0.78 to 1.00$)$ \\
\hline Unknown & $28(9.1)$ & $353(3.8)$ & 1.34 (0.79 to 2.27 ) & 0.64 (0.56 to 0.73 ) & 0.67 (0.59 to 0.76$)$ \\
\hline \multicolumn{6}{|l|}{ Type of patient } \\
\hline New patient/transfer in & $277(89.6)$ & $6497(70.4)$ & 1 (base) & 1 (base) & 1 (base) \\
\hline Relapse/Default/Failure & $32(10.4)$ & 2727 (29.6) & 4.19 (2.60 to 6.75$)$ & 7.97 (7.47 to 8.50$)$ & 7.81 (7.33 to 8.33 ) \\
\hline \multicolumn{6}{|l|}{ Sector } \\
\hline Public & $242(78.3)$ & $7692(83.4)$ & 1 (base) & 1 (base) & 1 (base) \\
\hline Private & $62(20.1)$ & $1373(14.9)$ & 0.93 (0.63 to 1.37$)$ & 0.85 (0.75 to 0.97$)$ & 0.85 (0.75 to 0.97 ) \\
\hline $\mathrm{FBOs}^{\mathrm{a}}$ & $5(1.6)$ & $159(1.7)$ & 0.62 (0.19 to 2.11$)$ & 0.99 (0.67 to 1.46 ) & 0.99 (0.68 to 1.45 ) \\
\hline \multicolumn{6}{|l|}{ Health Facility Level } \\
\hline Lower level ${ }^{\mathrm{b}}$ & $174(56.3)$ & $5737(62.2)$ & 1 (base) & 1 (base) & 1 (base) \\
\hline Higher level ${ }^{c}$ & $120(38.8)$ & $3165(34.3)$ & $1.18(0.80$ to 1.74$)$ & 0.91 (0.79 to 1.05$)$ & 0.91 (0.79 to 1.06$)$ \\
\hline Unknown & $15(4.9)$ & $322(3.5)$ & 1.99 (1.01 to 3.92$)$ & $1.01(0.82$ to 1.26$)$ & 1.04 (0.84 to 1.28$)$ \\
\hline \multicolumn{6}{|l|}{ Patient from an $\mathrm{Xpert}^{\oplus}$ site } \\
\hline Not from Xpert ${ }^{\oplus}$ site & $228(73.8)$ & $6778(73.5)$ & 1 (base) & 1 (base) & 1 (base) \\
\hline From $\mathrm{Xpert}^{\oplus}$ site & $81(26.2)$ & $2446(26.5)$ & $1.17(0.74$ to 1.85$)$ & 2.30 (1.86 to 2.82$)$ & 2.23 (1.82 to 2.74$)$ \\
\hline \multicolumn{6}{|c|}{ County Poverty Levels (from poorest to richest) } \\
\hline Quartile 1 & $53(17.2)$ & $1839(19.9)$ & 1 (base) & 1 (base) & 1 (base) \\
\hline Quartile 2 & $78(25.2)$ & $2875(31.2)$ & 0.85 (0.39 to 1.86$)$ & 1.22 (0.60 to 2.48$)$ & 1.19 (0.60 to 2.37$)$ \\
\hline Quartile 3 & $103(33.3)$ & $2802(30.4)$ & $1.04(0.48$ to 2.26$)$ & 1.34 (0.66 to 2.74$)$ & 1.32 (0.66 to 2.62$)$ \\
\hline Quartile 4 & $75(24.3)$ & $1708(18.5)$ & $0.54(0.25$ to 1.18$)$ & $0.64(0.32$ to 1.27$)$ & $0.62(0.32$ to 1.21$)$ \\
\hline \multicolumn{6}{|c|}{ Intra-class correlation coefficients (ICC) } \\
\hline County & & & 0.04 (0.02 to 0.11$)$ & 0.07 (0.04 to 0.11$)$ & 0.07 (0.04 to 0.11$)$ \\
\hline Health facility & & & 0.26 (0.18 to 0.37$)$ & $0.24(0.21$ to 0.27$)$ & 0.24 (0.21 to 0.27$)$ \\
\hline
\end{tabular}

${ }^{\mathrm{a}} \mathrm{FBO}$ s Faith Based Organisations

${ }^{b}$ Primary referral facilities

'Secondary and tertiary referral facilities

could be explained by private practice patients having to pay for tests to be done, and physicians may fail to comply with national guidelines, as seen in other settings [55-57].

\section{Limitations}

These data are from notification data which may be incomplete because an unknown number of cases may be treated but not reported. We additionally had no information on 
those in whom a test was done and not documented, or in whom a test was attempted but failed. A large proportion of relevant cases probably had no record of a test being done and no indication of why a test was not done.

This work, however, still provides much needed insights about the utilisation of diagnostic tests amongst those accessing health care who have been diagnosed and started on TB treatment. It also contrasts with the prevalence survey, where up to $40 \%$ of TB cases were missed and, thus, got no TB diagnostic tests. The guidelines recommend that all patients should have a bacteriological test prior to treatment. We evaluated, with the information available, how well the guidelines were being followed.

Our complete case analysis dropped approximately $3 \%$ of the cases due to missing data on facility, but this did not reduce our ability to make meaningful inferences. We also considered all the $0-14 y$ rs old as a single group but there may be differences in the sub categories. Because the numbers of children were low, subgroup analysis could have been misleading. This analysis together with the prevalence survey still provide deep insights into the known TB cases and guideline adherence, which can aid in planning services to improve TB case detection, especially in children.

\section{Conclusions}

Underuse of $\mathrm{Xpert}^{\circ}$ despite wide scale roll out and considerable investments undermines assertions of the cost-effectiveness of this technology. There is need to increase use of Xpert ${ }^{\circ}$, to ensure the correct patients are targeted for lengthy and potentially toxic TB treatment, and so that its potential advantages are realised and investments justified. Current focus on increasing access to $\mathrm{Xpert}^{\circ}$ is insufficient and more attention needs to be given to service delivery models that involve and educate staff and that address potential challenges of patient and specimen referral, with consideration needed for the private sector. Further research can support such efforts by identifying barriers and testing strategies to overcome these.

\section{Additional files}

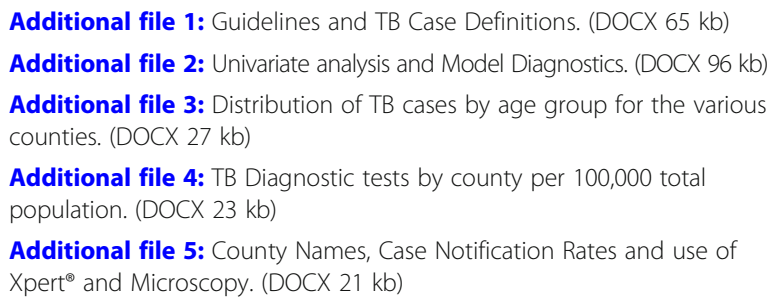

\section{Abbreviations}

AOR: Adjusted Odds Ratios; BMI: Body Mass Index; CNR: Case Notification rate; DR: Drug-resistant; FBO: Faith-Based Organisations; HIV: Human
Immune-deficiency Virus; IQR: Inter Quartile Ratio; LPA: Line Probe Assay; MDR-TB: Multidrug resistance Tuberculosis; NGO: Non-Governmental Organisations; SARAM: Services Availability and Readiness Assessment Mapping Report; TB: Tuberculosis; VIF: Variance Inflation Factor; WAZ: Weightfor-Age-Z score; WHO: World Health Organisation; Xpert ${ }^{\oplus}$ : Xpert MTB/RIF ${ }^{\oplus}$

\section{Acknowledgements}

The authors acknowledge Dr Kadondi Kasera, Martin Githiomi and Dr Kamene Kimenye of the Ministry of Health/National TB Programme for providing data and technical support; Kasia Stepniewska for statistical support; Professor Bob Snow and the Population Health Group of KEMRIWellcome Trust for providing health facility geo-codes, county population level data and supporting spatial analysis; and Dr Ben Marais for reading a draft of the manuscript and giving meaningful insights.

\section{Funding}

The lead author is a recipient of a Wellcome-Trust DELTAS scheme grant Initiative to Develop African Research Leaders (IDeAL) for her PhD studies.

\section{Availability of data and materials}

The datasets used and analysed for this study are stored in the KWTRP Research Data Repository, https://dataverse.harvard.edu/

dataset.xhtml?persistentld=doi:10.7910/DVN/TWHBY8, and can be made available via written request to the corresponding author and to the

National TB Programme, Ministry of Health, Kenya.

\section{Authors' contributions}

All authors contributed to conception and design; JNO, JM, IAK and EM were responsible for acquisition of the data; JNO conducted the analysis with additional support from JM, DG and PA. IAK, EM, AVH, MBVH and ME reviewed and approved the interpretation of data. JNO drafted the manuscript and all the other authors were involved in revising it critically for important intellectual content and gave final approval of the version to be published.

Ethics approval and consent to participate

Permission to analyse de-identified National TB programme data as part of a larger body of work to improve case detection for TB was granted by the KEMRI Scientific and Ethics Review Unit Committee (approval reference KEMRI/SERU/CGMR-C/076/3417), the National Commission for Science, Technology \& Innovation (Permit No. NACOSTI/P/18/56379/20603) and the National TB programme - Ministry of Health, Kenya.

Consent for publication

Not applicable

Competing interests

The authors declare that they have no competing interests.

\section{Publisher's Note}

Springer Nature remains neutral with regard to jurisdictional claims in published maps and institutional affiliations.

\section{Author details}

${ }^{1}$ KEMRI-Wellcome Trust Research Programme, Nairobi, Kenya. ${ }^{2}$ University of Nairobi, Department of Paediatrics and Child Health, Nairobi, Kenya. ${ }^{3}$ National TB and Leprosy Programme, Ministry of Health, Kenya, Nairobi, Kenya. ${ }^{4}$ World Health Organisation (Kenya), Nairobi, Kenya. ${ }^{5}$ The Academic Medical Centre, University of Amsterdam, Department of Global Health, Amsterdam, The Netherlands. ${ }^{6}$ Amsterdam Institute for Global Health and Development, Amsterdam, The Netherlands. ${ }^{7}$ Nuffield Department of Medicine, Oxford University, Oxford, UK.

Received: 9 March 2018 Accepted: 4 July 2018

Published online: 16 July 2018

\section{References}

1. World Health Organisation: Global Tuberculosis Report 2016. Geneva: World Health Organization; 2016.

2. Dodd PJ, Gardiner E, Coghlan R, Seddon JA. Burden of childhood tuberculosis in 22 high-burden countries: a mathematical modelling study. Lancet Glob Health. 2014;2(8):e453-9. 
3. World Health Organisation. Global Tuberculosis Report 2017. Geneva: World Health Organization; p. 2017.

4. Boyle D. Tuberculosis Diagnostics Technology Landscape 5th Edition: UNITAID; 2017. https://unitaid.eu/assets/2017-Unitaid-TB-DiagnosticsTechnology-Landscape.pdf

5. The end TB strategy. http://www.who.int/tb/End_TB_brochure.pdf.

6. Jenkins HE, Yuen CM, Rodriguez CA, Nathavitharana RR, McLaughlin MM Donald P, Marais BJ, Becerra MC. Mortality in children diagnosed with tuberculosis: a systematic review and meta-analysis. Lancet Infect Dis. 2017; 17(3):285-95.

7. Ministry of Health Kenya: Kenya Tuberculosis Prevalence Survey 2016. 2017.

8. du Preez K, Schaaf HS, Dunbar R, Swartz A, Bissell K, Enarson DA, Hesseling AC. Incomplete registration and reporting of culture-confirmed childhood tuberculosis diagnosed in hospital. Public Health Action. 2011;1(1):19-24.

9. Marais BJ, Graham SM, Cotton MF, Beyers N. Diagnostic and management challenges for childhood tuberculosis in the era of HIV. J Infect Dis. 2007; 196(Suppl 1):S76-85.

10. Marais BJ, Hesseling AC, Gie RP, Schaaf HS, Enarson DA, Beyers N. The bacteriologic yield in children with intrathoracic tuberculosis. Clin Infect Dis. 2006;42(8):e69-71.

11. Lessem E: The Tuberculosis Diagnostic Pipeline In: 2016 Pipeline Report. Edited by Treatment Action Group (TAG); 2016.

12. World Health Organisation: Policy statement: automated real-time nucleic acid amplification technology for rapid and simultaneous detection of tuberculosis and rifampicin resistance: Xpert MTB/RIF system. 2011.

13. World Health Organisation. Automated real-time nucleic acid amplification technology for rapid and simultaneous detection of tuberculosis and rifampicin resistance: Xpert MTB/RIF assay for the diagnosis of pulmonary and extrapulmonary TB in adults and children: policy update. Geneva: World Health Organisation; 2013.

14. World Health Organisation. Guidance for national tuberculosis programmes on the management of tuberculosis in children. Second ed. Geneva: World Health Organization; 2014

15. Division of Leprosy Tuberculosis and Lung Disease: Guidelines for the Management of Tuberculosis and Leprosy in Kenya. 2013.

16. Ministry of Health Kenya. National Guidelines on Management of Tuberculosis in Children. Kenya; 2013. p. 89.

17. Merab E. Hospitals to use new TB testing kit in war against disease. In: Daily Nation. Kenya: Nation Media Group; 2016.

18. Calligaro GL, Zijenah LS, Peter JG, Theron G, Buser V, McNerney R, Bara W, Bandason T, Govender U, Tomasicchio M, et al. Effect of new tuberculosis diagnostic technologies on community-based intensified case finding: a multicentre randomised controlled trial. Lancet Infect Dis. 17(4):441-50.

19. Rachow A, Clowes P, Saathoff E, Mtafya B, Michael E, Ntinginya EN, Kowour D, Rojas-Ponce G, Kroidl A, Maboko L, et al. Increased and Expedited Case Detection by Xpert MTB/RIF Assay in Childhood Tuberculosis: A Prospective Cohort Study. Clin Infect Dis. 2012;54(10):1388-96.

20. Coghlan R, Gardiner E, Amanullah F, Ihekweazu C, Triasih R, Grzemska M, Sismanidis C. Understanding Market Size and Reporting Gaps for Paediatric TB in Indonesia, Nigeria and Pakistan: Supporting Improved Treatment of Childhood TB in the Advent of New Medicines. PloS one. 2015;10(10):e0138323.

21. Bakeera SK, Wamala SP, Galea S, State A, Peterson S, Pariyo GW. Community perceptions and factors influencing utilization of health services in Uganda. Int J Equity Health. 2009;8(1):25.

22. Obrist B, Iteba N, Lengeler C, Makemba A, Mshana C, Nathan R, Alba S, Dillip A Hetzel MW, Mayumana I, et al. Access to Health Care in Contexts of Livelihood Insecurity: A Framework for Analysis and Action. PLoS Med. 2007;4(10)

23. Zhou C, Jiang W, Yuan L, Lu W, He J, Zhao Q, Xu B. Access to BacteriologicBased Diagnosis in Smear Positive Retreatment Tuberculosis Patients in Rural China: A Cross-Sectional Study in Three Geographic Varied Provinces. PloS One. 2016;11(1):e0146340.

24. Chiang SS, Roche S, Contreras C, Alarcon V, Del Castillo H, Becerra MC, Lecca L. Barriers to the diagnosis of childhood tuberculosis: a qualitative study. Int J Tuberc Lung Dis. 2015;19(10):1144-52.

25. Kiwanuka SN, Ekirapa EK, Peterson S, Okui O, Rahman MH, Peters D, Pariyo GW. Access to and utilisation of health services for the poor in Uganda: a systematic review of available evidence. Trans R Soc Trop Med Hyg. 2008; 102(11):1067-74

26. Frieze JB, Yadav R-P, Sokhan K, Ngak S, Khim TB. Examining the quality of childhood tuberculosis diagnosis in Cambodia: a cross-sectional study. BMC Public Health. 2017;17(1):232.
27. Donald PR. Childhood tuberculosis: the hidden epidemic. Int J Tuberc Lung Dis. 2004;8(5):627-9.

28. Zahra AS, George G. Absorptive capacity: a review, reconceptualization and extension. Acad Manage Rev. 2002;27(2):185-203.

29. Ministry of Health. Kenya Health Policy 2014-2030. Kenya: Ministry of Health Afya House Cathedral; 2014. http://www.health.go.ke.

30. Ministry of Health Kenya: Kenya Master Health Facilities List. 2016.

31. Ministry of Health Kenya: National Tuberculosis, Leprosy and Lung Disease Program Annual Report 2015. 2016

32. Masini E, Hanson C, Ogoro J, Brown J, Ngari F, Mingkwan P, Makayova J, Osberg M. Using Patient-Pathway Analysis to Inform a Differentiated Program Response to Tuberculosis: The Case of Kenya. J Infect Dis. 2017; 216(suppl_7):S714-23.

33. World Health Organisation: Definitions and reporting framework for tuberculosis- 2013 revision 2014.

34. Ministry of Health Kenya: Kenya Services Availability and Readiness Assessment Mapping (SARAM) Report. In. Edited by Organisation WH. Nairobi, Kenya; 2013.

35. CIDP County Integrated Development Plans [https://roggkenya.org/storysuggestions/kenya-county-cidp-kenya-five-year-plan-on-track/downloadpage-cidp-county-integrated-development-plans]. Accessed 17 Apr 2017.

36. Institute G. WorldPop Population Datasets: University of Southampton, Global Health Research Institue; 2015.

37. Linard C, Gilbert M, Snow RW, Noor AM, Tatem AJ. Population distribution, settlement patterns and accessibility across Africa in 2010. PloS One. 2012; 7(2):e31743.

38. StataCorp: STATA Multi-Level Mixed-Effects Reference Manual: Release 13. In. 4905 Lakeway Drive, College Station, Texas 77845: Stata Press; 2013: 371.

39. Yuan Y, Johnson VE. Goodness-of-fit diagnostics for Bayesian hierarchical models. Biometrics. 2012;68(1):156-64.

40. Marais BJ. Childhood tuberculosis: epidemiology and natural history of disease. Indian J Pediatr. 2011;78(3):321-7.

41. Dangisso MH, Datiko DG, Lindtjørn B. Low case notification rates of childhood tuberculosis in southern Ethiopia. BMC Pediatr. 2015;15:142

42. Tsofa B, Goodman C, Gilson L, Molyneux S. Devolution and its effects on health workforce and commodities management - early implementation experiences in Kilifi County, Kenya. Int J Equity Health. 2017:16:169

43. Detjen AK, DiNardo AR, Leyden J, Steingart KR, Menzies D, Schiller I, Dendukuri N, Mandalakas AM, Xpert MTB. RIF assay for the diagnosis of pulmonary tuberculosis in children: a systematic review and meta-analysis. Lancet Respir Med. 2015;3(6):451-61.

44. Steingart KR, Sohn H, Schiller I, Kloda LA, Boehme CC, Pai M, Dendukuri N. Xpert(R) MTB/RIF assay for pulmonary tuberculosis and rifampicin resistance in adults. Cochrane Database Syst Rev. 2013;1:Cd009593.

45. Theron G, Zijenah L, Chanda D, Clowes P, Rachow A, Lesosky M, Bara W, Mungofa S, Pai M, Hoelscher M, et al. Feasibility, accuracy, and clinical effect of point-of-care Xpert MTB/RIF testing for tuberculosis in primary-care settings in Africa: a multicentre, randomised, controlled trial. Lancet. 2014; 383(9915):424-35.

46. Vassall A, Siapka M, Foster N, Cunnama L, Ramma L, Fielding K, McCarthy K, Churchyard G, Grant A, Sinanovic E. Cost-effectiveness of Xpert MTB/RIF for tuberculosis diagnosis in South Africa: a real-world cost analysis and economic evaluation. Lancet Global Health. 2017;5(7):e710-9.

47. Cowan J, Michel C, Manhiça I, Monivo C, Saize D, Creswell J, Gloyd S, Micek M. Implementing rapid testing for tuberculosis in Mozambique. Bull World Health Organ. 2015;93(2):125-30.

48. Hanrahan CF, Haguma P, Ochom E, Kinera I, Cobelens F, Cattamanchi A, Davis L, Katamba A, Dowdy D. Implementation of Xpert MTB/RIF in Uganda: Missed Opportunities to Improve Diagnosis of Tuberculosis. Open Forum Infect Dis. 2016:3(2):ofw068.

49. Bacha JM, Ngo K, Clowes P, Draper HR, Ntinginya EN, DiNardo A, Mangu C, Sabi I, Mtafya B, Mandalakas AM. Why being an expert - despite xpert -remains crucial for children in high TB burden settings. BMC Infect Dis. 2017:17(1):123.

50. Ardizzoni E, Fajardo E, Saranchuk P, Casenghi M, Page AL, Varaine F, Kosack CS, Hepple P. Implementing the Xpert(R) MTB/RIF Diagnostic Test for Tuberculosis and Rifampicin Resistance: Outcomes and Lessons Learned in 18 Countries. PloS One. 2015;10(12):e0144656.

51. Mulder C, Harting J, Jansen N, Borgdorff MW, van Leth F. Adherence by Dutch public health nurses to the national guidelines for tuberculosis contact investigation. PloS One. 2012;7(11):e49649. 
52. Kanjee Z, Amico KR, Li F, Mbolekwa K, Moll AP, Friedland GH. Tuberculosis infection control in a high drug-resistance setting in rural South Africa: information, motivation, and behavioral skills. J Infect Public Health. 2012:5(1):67-81.

53. Brouwer M, Coelho E, Mosse C, Brondi L, Winterton L, van Leth F. Healthcare workers' challenges in the implementation of tuberculosis infection prevention and control measures in Mozambique. PloS one. 2014; 9(12):e114364.

54. Tebruegge M, Ritz N, Koetz K, Noguera-Julian A, Seddon JA, Welch SB, Tsolia M, Kampmann B. Availability and use of molecular microbiological and immunological tests for the diagnosis of tuberculosis in europe. PloS One. 2014;9(6):e99129.

55. Lei X, Liu Q, Escobar E, Philogene J, Zhu H, Wang Y, Tang S. Public-private mix for tuberculosis care and control: a systematic review. Int J Infect Dis. 2015:34:20-32

56. Uplekar M. Involving private health care providers in delivery of TB care: global strategy. Tuberculosis (Edinb). 2003;83(1-3):156-64.

57. Bell CA, Duncan G, Saini B. Knowledge, attitudes and practices of private sector providers of tuberculosis care: a scoping review. Int J Tuberc Lung Dis. 2011;15(8):1005-17.

Ready to submit your research? Choose BMC and benefit from:

- fast, convenient online submission

- thorough peer review by experienced researchers in your field

- rapid publication on acceptance

- support for research data, including large and complex data types

- gold Open Access which fosters wider collaboration and increased citations

- maximum visibility for your research: over $100 \mathrm{M}$ website views per year

At BMC, research is always in progress.

Learn more biomedcentral.com/submissions 